\title{
GÉNERO, SALUD Y DERECHOS FUNDAMENTALES: REFLEXIONES EN TORNO A UN PROYECTO DE LEY SOBRE PREVENCIÓN DE DEFECTOS CONGÉNITOS
}

\author{
Paula Siverino Bavio ${ }^{1}$ \\ Profesora Titular de Derecho Civil y de Bioética \\ Pontificia Universidad Católica del Perú \\ e Inca Garcilaso de la Vega, Perú.
}

\section{INTRODUCCIÓN}

El presente trabajo intenta reflexionar, en torno a un proyecto de ley argentino, sobre un tema actual: la perspectiva de género en la elaboración de las políticas de salud, desde una perspectiva de la bioética de los derechos humanos.

Para ello se presenta el estado actual de la cuestión en Argentina respecto de la génesis legislativa y los antecedentes jurisprudenciales que desencadenaron las leyes en materia de prevención de defectos congénitos: hablamos del dilema generado a raíz de los planteos de mujeres embarazadas que al tomar conocimiento que el feto que gestan padece una patología incompatible con la vida extrauterina llamada anencefalia, reclaman la posibilidad de recurrir a un aborto.

Habiendo abordado en otras ocasiones este tema, ${ }^{2}$ nos centramos aquí en un aspecto menos estudiado pero esencial en materia de protección de los derechos de la persona por nacer y de la salud reproductiva de las mujeres, la prevención de defectos congénitos a través de una política de fortalecimiento de harinas.

\footnotetext{
Abogada y candidata al doctorado por la Universidad de Buenos Aires. Recibido el 24 de julio de 2009. Siverino BAvio, Paula "Algunas cuestiones éticas y jurídicas sobre anencefalia" en Persona, Revista sobre Derechos Existenciales, Nro. 19, año 2003 http://revistapersona.4t.com/19Bavio.htm; "Comentario a la ley 1044. Embarazos incompatibles con la vida". Publicado en Revista La Ley, septiembre 2003. LL ADLA LXIII -D, pp. 4929-4937; “Anencefalia y legislación” Programa Infosalud, Año 4, N 1000, edición especial, pp. 108-9, Buenos Aires, Producciones Infoprogramas SH Noviembre 2003; "Anencefalia, la reacción legislativa” Revista Jurídica del Perú, Año LIII, Nro. 46, mayo, 2003; “¿Zapatero, a tus zapatos? (a propósito de los fallos sobre anencefalia)", Gaceta Jurídica, Diálogos con la Jurisprudencia, Año $8 \mathrm{~N}^{\circ}$ 51, diciembre 2002, Jurisprudencia extranjera comentada, Lima, Perú, pp. 113-128.
} 
Creemos que este debate puede aportar elementos a la discusión peruana donde, aun contando con el antecedente del caso de Karen Llantoy, los interrogantes abiertos por la decisión del Comité de Derechos Humanos en el particular están aún pendientes de resolución.

\section{EVOLUCIÓN DE LA CUESTIÓN}

El 21 de agosto del año 2008 ingresó por mesa de entradas del Senado de la Nación argentina el expediente 55/08, el que da cuenta de la sanción, el día 20 de agosto por parte de la Cámara de Diputados, del proyecto de ley que modifica los artículos 3, 4 y 5 de la ley $\mathbf{2 5 . 6 3 0}$ del año 2002, ley que creó la Campaña Nacional para la Prevención de Malformaciones del Nacimiento en el cerebro, la médula espinal y otros órganos a través del enriquecimiento de la harina de trigo y sus productos derivados.

La propuesta, girada para su discusión a la Comisión de Salud y Deportes del Senado, generó una viva respuesta de los sectores médicos, entre los que destaca la carta dirigida por la Sociedad Argentina de Pediatría a la presidenta de dicha Comisión, solicitando la no aprobación del proyecto de ley, por entender que las modificaciones propuestas serían un grave retroceso en términos de salud pública. Desde la Comisión ha trascendido que el proyecto sería objeto de cambios.

El tema no es menor, involucra la salud de millones de mujeres, particularmente aquellas en edad fértil y también la de sus hijos por nacer, dado que el fortalecimiento de harinas ha demostrado ser una de las herramientas de amplio alcance más sencillas, económicas y eficaces para la prevención de defectos congénitos relacionados con la carencia de ácido fólico. Por otra parte, la legislación argentina, al igual que la peruana, no contempla la posibilidad de interrumpir el embarazo en casos de defectos graves del feto, como son los provocados por defectos en el cierre del tubo neural -causados básicamente por la carencia de ácido fólico- lo cual abre otro frente de conflicto, tal como lo han acreditado los diversos casos que tomaron estado público donde se "pedía autorización" para interrumpir el embarazo de un feto anencefálico.

Proponemos entonces, hacer un breve recorrido que nos permita, teniendo en cuentas las razones que originaron la sanción de la ley, reflexionar sobre el proyecto de ley que la modifica, a entender de algunos, sustancialmente.

\section{ANTECEDENTES JURISPRUDENCIALES}

En la Argentina, entre los años 2000 y 2002 se hicieron públicos numerosos casos judiciales en los que se solicitaba una orden o autorización ${ }^{3}$ para la interrupción del

3 En algunos casos se solicitó la orden, tal el caso de "TS", en otros, se autorizara la práctica en cuestión, en estos últimos habitualmente la institución asistencial negaba su posición de confrontación, y pretendía ser eximida de las cosas del pleito. 
embarazo o bien la inducción al parto de un feto anencefálico. El más notorio de ellos, el fallo "TS" pese a lo cual, cinco meses después la Suprema Corte de la Provincia de Buenos Aires, desconociendo este antecedente falló en sentido contrario en un caso de idénticas características. ${ }^{6}$ Vale decir que cuando este caso llegó a la Corte Suprema de la Nación ésta revalidó su doctrina, dejando sin efecto lo decidido por la Suprema Corte de la Provincia de Buenos Aires, y que el pronunciamiento devino abstracto ya que el feto del caso "B.A." nació y falleció antes de la emisión del fallo. Posteriormente la Suprema Corte de la Provincia de Buenos Aires cambió su composición y asimismo su doctrina en el tema. ${ }^{7}$

Observamos que como reacción frente a estos casos, que tuvieron un alto impacto mediático, han habido básicamente dos respuestas o enfoques legislativos complementarios: uno centrado en la situación que tiene lugar entre el médico y la paciente embarazada, frente a la posibilidad de interrumpir la gestación o adelantar el parto, ante una pretendida colisión con la normativa que prohíbe el aborto voluntario (en este orden se inscribe la ley 1044 de la Ciudad de Buenos Aires) y por otro lado, la implementación de una política de prevención de defectos congénitos, que culminó con la sanción de una norma nacional, la ley $25.630 / 2002$, cuyo proyecto de modificación motiva el presente comentario.

La discusión en torno al tema es amplia y compleja, abarcativa de cuestiones que comentamos en su oportunidad ${ }^{8}$ y cuyo tratamiento excede en mucho el presente trabajo. Considerando estas limitaciones, y dado que la ley refiere a la prevención de defectos congénitos del tubo neural, pasaremos a exponer brevemente en qué consiste una de las patologías prevalentes involucradas en este debate, la anencefalia, para tener una aproximación más directa a los bienes jurídicos en juego.

\section{QUÉ TIPO DE PATOLOGÍA ES LA ANENCEFALIA}

Los defectos congénitos son un grupo numeroso de padecimientos muy heterogéneos cuya causa en ocasiones es desconocida e incierta. Actualmente representan un importante problema de salud en el mundo, por ser una de las causas principales de

A los cinco meses de gestación, la Sra. ST se entera mediante una ecografía que el feto que lleva en su vientre padece de anencefalia, solicita una inducción al parto, en la Maternidad Sardá le recomiendan la inducción, pero le exigen orden del juez para hacerlo, presenta un amparo en la justicia en lo Contencioso administrativo, la jueza se declaró incompetente, apela la fiscalía, la Cámara obliga a la jueza a resolver y esta deniega la autorización. Apela la actora y la Cámara confirma el fallo, apela y finalmente el Tribunal Superior de la Ciudad de Buenos Aires por cuatro votos a uno (con disidencia del Dr. Casás) otorga la autorización, llegando el caso a la Corte Suprema de Justicia por vía del recurso extraordinario interpuesto por la asesora general de menores e incapaces. La Corte confirma el fallo del Tribunal Superior.

5 CSJN, sentencia del 11/'1/02 Exp. 715/00 "Tanus Silvia c/ Gobierno de la Ciudad s/ amparo”.

6 SCBA “B.A. S/ autorización judicial” acuerdo 82058, sentencia del 22/6/01.

7 SCBA Ac. 85.566, «Hospital Interzonal de Agudos Eva Perón de Gral. San Martíns/ Autorización» publicado en www.diariojudicial.com noticia del 8/8/02

8 Siverino Bavio, Paula. Anencefalia, en Garay, Óscar, Derecho fundamentales de los pacientes, Ad Hoc, 2003. 
morbilidad y mortalidad perinatal e infantil. Los defectos de nacimiento más frecuentes y estudiados son los defectos del tubo neural, que incluyen la anencefalia, encefalocele y mielomelingocele. ${ }^{?}$

La anencefalia es una anomalía neurológica congénita, es una de las alteraciones en la formación del cerebro resultante de la falla en etapas precoces del desarrollo embrionario del mecanismo de cierre del tubo neural llamado de inducción dorsal. Se caracteriza por la falta de huesos craneanos (frontal occipital y parietal) hemisferios y la corteza cerebral. El tronco cerebral y la médula espinal están conservados aunque en muchos casos se acompaña con defecto de cierre de la médula espinal, mielomeningocele. La anencefalia se distingue claramente de otros defectos de la inducción dorsal por el aspecto de "rana" de los pacientes afectados en los que hay una falta total de calota craneana y cobertura de las estructuras neurológicas restantes El defecto es cubierto por una membrana gruesa del estroma angiomatoso, pero nunca por hueso o piel normal; la ausencia o destrucción del cerebro es sustituida por una masa rudimentaria de tejido mesenquimático y ectodérmico. Alrededor del 75\% de los fetos afectados muere intraútero y del $25 \%$ del restante nacido vivos, de los cuales el $57 \%$ fallece dentro de las primeras horas y alrededor del $15 \%$ fallece dentro de los tres días, las sobrevidas más largas son excepcionales. ${ }^{10}$

En la anencefalia la inexistencia de las estructuras cerebrales (hemisferios y corteza) con la sola presencia del tronco cerebral provoca la ausencia de todas las funciones superiores del sistema nervioso central que tienen que ver no solo con la parte motora, sino con la existencia de la conciencia y que implican la cognición, la vida de relación, comunicación, afectividad, emotividad; manteniendo tan solo la presencia efímera de las funciones vegetativas que controlan parcialmente la respiración, las funciones vasomotoras y las dependientes de la médula espinal.

Un feto o posteriormente un nacido anencéfalo carece por completo y de forma irreversible de funciones motoras y cognoscitivas; la anencefalia es el equivalente en los niños al estado vegetativo permanente ${ }^{11}$ (EVP) que implica la perdida absoluta de

9 Secretaría de Salud, Dirección Adjunta de Salud Perinatal. "El ácido fólico y la prevención de defectos congénitos", México, 2003, p. 9.

10 No debe ser confundida con otras patologías más benignas como la excencefalia, inencefalia, cefaloceles, mieloceles o mielomeningoceles; el pronóstico funcional en estos últimos dos casos va a depender de la existencia o desarrollo de la hidrocefalia asociada y aunque más del $50 \%$ de los pacientes requieren de la colocación de una válvula de derivación, el pronóstico neurológico es relativamente bueno en lo relativo a funciones cognitivas e intelectuales. Hay otras patologías por defectos en el tubo de inducción ventral, así la holoprosencefalia, donde el tejido cortical ha sido reemplazado por líquido cefaloraquideo debido a un infarto masivo o a infección uterina, siendo la calota craneana normal y la hidranecefalia que no deben confundirse con la anencefalia. Gherard. Carlos; Kurlat, Isabel. Anencefalia e interrupción del embarazo. Separata de Nueva Doctrina Penal-2000 B.

11 El EVP es un estado de inconsciencia permanente con pérdida total de las funciones corticales, nopercepción de sí mismo ni del medio con persistencia de los ciclos de sueño y vigilia (The medical task force on anencephaly. The infant with anencephaly, The New England Journal of Medicine; Vol. 322 $\mathrm{N}^{\circ}$ 10, March 8, 1990, p. 669). 
conciencia, la afectividad y la comunicación, con conservación de los ciclos sueñovigilia, reflejos y movimientos oculares, respiración espontánea reflejos protectores del vómito y la tos. ${ }^{12}$

\section{EL CONTEXTO SOCIAL Y EL INFORME DE LA DEFENSORÍA DEL PUEBLO}

La discusión a la que pretendemos aproximarnos se inserta en una realidad socio económica (tanto en la Argentina como en el Perú) que pese a ostentar cifras records en lo macroeconómico, convive como un hecho incontrastable con los elevadísimos índices de personas sobreviviendo bajo el índice de pobreza, y preocupantes y aún no resueltos índices de mal nutrición y desnutrición materno-infantil, advertida desde hace tiempo en hospitales y centros de atención primaria.

El ácido fólico es un compuesto esencial en la prevención de ciertas anemias. Este compuesto, considerado también como vitamina Bgr es sintentizada por bacterias y mohos, por lo que pueda obtenerse como subproducto de la producción de antibióticos. El organismo humano no puede sintetizar ácido fólico con lo cual depende enteramente de la ingesta de los alimentos. ${ }^{13}$

En 1968 se describió por primera vez la relación entre niveles bajos de folatos en la gestación y defectos del tubo neural. Trayendo a colación la experiencia mexicana, en 1992 se recomienda la ingesta de $0,4 \mathrm{mg} /$ día de ácido fólico a mujeres en edad reproductiva, para 1995 se permitió la suplementación de los cereales con ácido fólico y es hasta 1998 cuando se lleva a cabo la suplementación de harinas comerciales con 0,140 mg de ácido fólico cada $100 \mathrm{mg}$ de harina con lo que se añade $0,1 \mathrm{mg} /$ día a la dieta norma, aconsejándose incrementar la suplementación a 0,350 mg por $100 \mathrm{mg}$ de harina. ${ }^{14}$

Como es sabido, una forma de paliar las deficiencias nutricionales de las mujeres en edad fértil, que posteriormente redundarían en nacimientos de niños con serias malformaciones, involucra una regulación para la prevención de defectos congénitos, con disposiciones concretas, como aquellas que disponen enriquecer ciertos productos básicos, como las harinas para panificación con ácido fólico, tal como se lleva a cabo con éxito en diversos países como Chile, México, EE.UU., Hungría y desde el 2002, Argentina.

El cincuenta por ciento de las malformaciones congénitas puede prevenirse y constituye un principio de responsabilidad moral para las autoridades sanitarias, para la sociedad y para los profesionales de la salud estar informados y actuar en consecuencia. ${ }^{15}$

12 Gheraradi-Kurlat, op. cit.

13 Secretaría de Salud, Dirección Adjunta de Salud materna y perinatal “El ácido fólico...”, p. 16.

14 Op. cit., p. 10.

15 NAzer, Julio. “Prevención primaria de los defectos congénitos”. Rev. Médica Chile, 2004, 132: 502. 
Desde esta percepción, en la Ciudad Autónoma de Buenos Aires, la Defensoría del Pueblo de la Ciudad inició de oficio la actuación n 1681/01 para "determinar si la ingesta de ácido fólico antes de la fecundación es un recurso esencial para prevenir malformaciones fetales tales como la anencefalia, espina bífida y otras"; Ilevando a cabo un relevamiento en los servicios de Ginecología y Obstetricia de la ciudad, concluyendo que si bien son varias los factores que se asocian con el aumento de la incidencia de diversos tipos de malformaciones congénitas (edad de los padres, estación del año; el país de residencia, la raza y las tendencias familiares),${ }^{16}$ entre un cincuenta y un setenta y cinco por ciento de los casos son causados por insuficiencias en la alimentación de las mujeres, en particular por la falta de ingesta de ácido fólico en cantidades apropiadas.

Asimismo un porcentaje importante se produce por la mala asimilación de ácido fólico como consecuencia de la consumo de medicamentos tales como anticonceptivos orales, estimulantes de la ovulación, diuréticos, antiparasitarios y antibacterianos, entre otros. ${ }^{17}$ El informe concluye que si bien se encuentran disponibles técnicas preventivas de este tipo de malformaciones, "no se han diseñado políticas sanitarias responsables".

Por otra parte, el informe de la Defensoría formula una fuerte denuncia contra los profesionales de la salud en tanto surge, a lo largo de las entrevistas, una carencia en la información provista a las mujeres en situación o expectativa de llevar adelante un embarazo, concretamente la advertencia de las necesidades dietarias y el daño irreversible que ciertos productos o comportamientos pueden ocasionar a la mujer embarazada, especialmente durante el primer trimestre del embarazo, conductas concretas que violentarían el derecho a la salud y a la procreación sana y responsable, tutelados por la Constitución Nacional y Tratados internacionales, la Constitución de la ciudad, la Ley General de Salud y la Ley de Salud Reproductiva, que garantizan el derecho de los padres, y especialmente de la mujer a disponer de toda la información necesaria para planificar y llevar adelante un embarazo en la mejores condiciones disponibles. Pero además, como manifiesta el informe "nada se dice de la obligación del Estado de proveer gratuitamente ácido fólico en los servicios de salud”. ${ }^{18}$

Dados los niveles de mal nutrición y desnutrición que afectan a una enorme cantidad de personas en Argentina, y particularmente a mujeres en edad fértil y embarazadas, es de esperar un aumento en el número de embarazos de fetos con defectos congénitos (DC). Se planteó entonces, si era deber del Estado tomar medidas concretas de acción y prevención.

Se ha sostenido que un programa de prevención de defectos congénitos, podría establecer al menos tres estrategias alternativas: 1) La libre opción, es decir promover un programa voluntario de ingesta permanente, que requeriría de una campaña educativa, con un costo de mínimo a mediano, y aseguraría una eficacia mínima, privile-

16 Carlston, Bruce. Embriología humana y desarrollo biológico. Madrid, Harcourt, 2000, p. 135.

17 Defensoría del Pueblo de la Ciudad Autónoma de Buenos Aires, Res.0750/01.

18 Ibíd. 
giando el criterio individual; 2) La distribución gratuita de complejos nutricionales, con una inversión mediana, que incluyera campaña educativa e implementación de un sistema de distribución. La tercera opción, 3) contempla la fortificación de alimentos, la que es percibida como de alto costo para el Estado, pero de máxima eficacia al alcanzar a toda la población. ${ }^{19}$

En este entendimiento, a fines de agosto de 2002 fue promulgada la ley $25.630,{ }^{20}$ siendo su objeto "la prevención de las anemias y malformaciones del tubo neural, tales como la anencefalia y la espina bífida”, disponiendo el enriquecimiento de la harina de trigo destinada al consumo. La iniciativa, en la que participó el Ministerio de Salud, y se originó en Diputados, fue modificada en el Senado, siendo sancionada en julio de 2002.

\section{ANTECEDENTES DE LA LEY 25.630}

Siguiendo la genealogía de la norma, vemos que los proyectos presentados (Galland y otros, 2.471-D-2000; Galland y otros 2472-D-2000 y Fayland y otros, 1721-D2001) ${ }^{21}$ fueron girados para su examen a las Comisiones de Acción Social y Salud Pública, de Industria, Familia, Mujer y Minoridad, resolviendo, luego de su análisis, despacharlo unificado en un solo dictamen, modificando alguno de sus aspectos.

La versión aprobada, modifica el objeto de la ley, que en el proyecto de Galland y otros consistía en "[la creación de] la Campaña Nacional de Prevención de Malformaciones de Nacimiento en el cerebro y la Médula espinal, la que se declara de interés nacional" (art. 1) estableciendo una comisión asesora ad honorem, de seguimiento y control, para controlar el desarrollo del programa, así como la elaboración de encuestas y bases de datos (arts. 6 y 7 ).

Un segundo proyecto disponía "la fortificación y/o enriquecimiento de los productos alimenticios sobre la base de harinas de trigo, productos alimenticios de cereal, bebidas fortificantes instantáneas en polvo, leches descremadas, enteras o cultivadas, mediante la inclusión de ácido fólico...".

El proyecto de Fayland, proponía "[que] las harinas que se produzcan o elaboren para el consumo humano, dentro del territorio de la República Argentina, así como las que se importen a tal fin, se las deberá adicionar obligatoriamente con ácido fólico en las proporciones a determinar...".

El dictamen unificó los proyectos, sintetizando las disposiciones concretas relativas a la campaña de prevención en el artículo décimo, que preveía la implementación de una amplia campaña de difusión para informar "los beneficios de la incorporación

ROUBICEK, Martin, op. cit.

20 Ley 25.630 BO N $29.968,1^{\text {a }}$ sección, del 23 de agosto de 2002.

21 Orden del día $n^{\circ}$ 3398, Sesiones ordinarias 2001. Cámara de Diputados de la Nación. TP 46/2000. 
del sulfato ferroso, del ácido fólico, la tiamina, la riboflavina y niacina en las harinas destinadas a la panificación”.

Dicho dictamen no es del todo claro al establecer el ámbito de aplicación, ya que el art. 3 refiere al enriquecimiento de "harinas de trigo destinada al consumo que se comercializa en el mercado nacional", mientras que en el art. 10 el enriquecimiento se circunscribió a las "harinas de trigo para panificación". Se agregaron otros nutrientes además del ácido fólico y se creaba una comisión asesora para el seguimiento de la ley en el marco del Programa Nacional de Salud Materno Infanto Juvenil (art. 9).

Con posterioridad a su aprobación en la Cámara Baja pasó al Senado de la Nación, donde fueron debatidos en la sesión del 25/03/02 los dictámenes C.D. 155/01, S.1.199/ 01, S. 495/02 y S. 518/02, luego del paso del proyecto girado por las comisiones de Asistencia Social y Salud Pública, Legislación General y Comercio.

Fueron presentados tres proyectos (Molinari Romero, Perceval, otros integrantes de la comisión, y Maza), introduciéndose cambios en la propuesta original. Se modificó el art. 3, en cuanto a los porcentajes de nutrientes que deben agregarse en la harina, establecidos de acuerdo con las conversaciones que las distintas comisiones mantuvieron con la UNICEF y con especialistas en alimentos, que plantearon cómo se ha estado trabajando en Chile y en otros países a los que es exportada la harina con estos nutrientes ya introducidos. ${ }^{22}$ Se agregó asimismo, un artículo que exime del enriquecimiento a aquellos productos destinados a personas cuyos requerimientos dietarios exigen la ausencia de los mismos; y se eliminó la propuesta de adhesión de las provincias, por tratarse de una ley nacional. ${ }^{23}$

El proyecto con sus modificaciones fue aprobado en una brevísima sesión con tan solo dos intervenciones (Maza y Percival) y sin mediar prácticamente exposiciones dado que al momento de la discusión se encontraba el recinto al límite del quórum, motivo por el cual, se decidió aprobar la ley sin mayor debate a fin de evitar el riesgo de perder la posibilidad de votar la norma.

Tal como hemos mencionado, inicialmente, la propuesta refería solamente al enriquecimiento de las harinas de trigo destinadas a panificación, pero en el proceso de consenso se decidió extender esta previsión a todas las harinas de trigo de consumo interno -lo que mereció en su momento la objeción de la senadora Perceval, quien recordó la advertencia hecha por los organismos consultados, quienes habían recomendado la fortificación de las harinas para panificación- generando un obstáculo en su aplicación concreta debido a las dificultades tecnológicas inherentes al proceso, ya que esta norma obliga a las empresas, productores, etcétera, que trabajen con harina de trigo y sus productos derivados directos a realizar el enriquecimiento de todas las

\footnotetext{
22 Sesión del 30/5/02, del discurso de la senadora Maza, http://proyectos.senado.gov.ar/wa/web/owai/ 230502.html

23 ibíd.
} 
harinas, siendo, en caso de infracción, pasibles de las penalidades que marca el artículo 9 de la ley 18.284 .

De regreso a Diputados para su estudio, el proyecto fue aprobado con sus modificaciones en la sesión del 31/7/02. ${ }^{24}$

La reglamentación inicialmente propuesta por el Ministerio de Salud, fue derivada al SENASA en febrero del año 2003, para pasar a su examen en la ANMAT. Luego de su estudio técnico en el INAL (Instituto Nacional de Alimentos), fue sancionada en agosto de 2003, mediante el decreto reglamentario 597/2003.

\section{LA LEY 25.630}

Tal como se ha dicho, la ley 25.630, de once artículos, es sancionada el 31 de julio y promulgada el 22 de agosto de 2002 . Entre sus disposiciones fundamentales estableció lo siguiente:

1. Su objeto es la prevención de anemias y malformaciones del tubo neural (art. 1).

2. El Ministerio de Salud, a través del INAL, es el organismo de control de la ley (art. 2),

3. La harina de trigo destinada al consumo que se comercializa en el mercado nacional debe ser adicionada de los siguientes nutrientes: hierro, ácido fólico, tiamina, riboflavina, riacina, en las proporciones establecidas (art. 3).

4. Están exceptuadas de lo establecido en el artículo 3 la harina de trigo destinada a la producción de productos dietéticos que precisen mayor o menor cantidad de nutrientes (art. 4).

5. Los productos elaborados con harina de trigo enriquecida deben consignar la cantidad de cada nutriente en sus envases (art. 5).

6. Las infracciones a la ley y el decreto reglamentario pueden dar lugar a las penalidades del artículo 9 de la ley 18. 248 (art. 6).

Por su parte, el decreto reglamentario 597/2003 crea en su artículo 2 una Comisión de asesoramiento para el examen de los productos, siendo su cometido analizar los estudios de resultados de factibilidad, estabilidad y lapsos de aptitud de los productos, a efectos de sugerir a la autoridad un trámite de excepción si los estudios fueran negativos.

El artículo 3 establece los plazos para que los productores tomen los recaudos necesarios y realicen los estudios de factibilidad, estabilidad y aptitud: así fija para las harinas de panificación y harinas de venta directa al público noventa días desde la entrada en vigencia de la presente medida; para las pastas secas, ciento ochenta días; y para los productos de alta actividad acuosa y/o materia grasa, doscientos cuarenta días. El artículo 4 refiere a exigencias administrativas respecto de los plazos para declarar la nueva fórmula.

24 Vid HCD, Orden del día $\mathrm{N}^{\circ}$ 661, Comisiones de Acción Social y Salud Pública, de Industria y Familia, Mujer, Niñez y Adolescencia. 
El decreto reglamentario posee en anexo I. Las principales prescripciones del anexo son las que siguen;

1. La ley y el decreto reglamentario se aplican a todas las harinas de trigo que se usan para consumo humano en el país sean nacionales o importadas, para su consumo directo o procesadas (art. 1).

2. Se entiende por "harina enriquecida" la adicionada con los nutrientes del artículo 3 de la ley 25.360, con el objeto de resolver carencias de alimentación (art. 2).

3. Debe utilizarse harina enriquecida para la elaboración de productos alimentarios, con excepción de los productos dietéticos, de exportación y harinas de exportación (art. 3).

4. En los envases de los productos que contengan harina enriquecida debe constar esta circunstancia (art. 4).

5. La garantía de calidad y control interno de la harina de trigo enriquecida es responsabilidad de los industriales (art. 5).

6. La ANMAT llevará una base de datos para registrar los establecimientos productores de harina en el país (art. 6).

7. El proyecto de ley para modificar la ley 25.630.

La norma tuvo un primer intento de cambio, que obtuvo media sanción en la Cámara de Diputados en septiembre del año 2006, originada en modificaciones propuestas por un proyecto del Ejecutivo de febrero de ese año, que perdiera estado parlamentario y fuera presentado nuevamente en el año 2008 , con el número de expediente 0799-D-2008, trámite parlamentario 011 del 17 de marzo del año 2008.

A fines de agosto del corriente, el proyecto de ley fue aprobado en una maratónica sesión de la Cámara de Diputados que votó 552 proyectos en dos días, en la cual se aprobaron ochenta proyectos de ley, entre ellos veinticuatro con sanción definitiva.

El proyecto del Ejecutivo plantea que la comisión de asesoramiento, quien se dedicó a evaluar los exámenes de factibilidad presentados por varias empresas de producción masiva, así como a recopilar bibliografía específica concluyó que "en alimentos de alta actividad acuosa, como las pastas y las tapas para empanadas, y las de alta materia grasa, como ciertos tipos de bizcochos y galletitas, se produce una alteración organolépticas", comprobando entre otros alteraciones del color y el sabor debido al proceso de oxidación del ión ferroso, que producen rechazo en el consumidor.

Además "el proceso catalítico mencionado afecta nutrientes tales como vitaminas y aminoácidos, disminuyendo el carácter nutritivo de los alimentos... y no sería posible asegurar su inocuidad frente a la presencia de radicales libres". ${ }^{25}$ En igual sentido manifiesta que "luego de evaluar distintas alternativas a los casos que fundamentaban dificultades de naturaleza tecnológicas presentados con el hierro en productos de alta actividad acuosa o alto contenido graso se propone modificar la ley".

25 Sesiones del día, Cámara de Diputados de la Nación, Orden del Día Nro. 1172, Comisión de Acción Social y Salud e Industria. 
En función de estas razones, el proyecto propone modificar el artículo 3 de la ley, limitando la obligación de fortificación sólo a la harina de trigo destinada a la elaboración de pan francés y criollo, destinado al envase para la venta directa. Asimismo se modifica el índice de medición de "Niveles de adición" (de los nutrientes) a "Niveles mínimos totales de los nutrientes", sin necesidad de diferenciar entre los nutrientes propios de la harina y los adicionados, lo que presentaba problemas para su correcto control. Adicionalmente se propone derogar el artículo 4 de la ley y cambiar el artículo 5 que establece la obligatoriedad de la rotulación, ya que al ser el pan del día el único comprendido por la norma modificada, éste se encuentra exceptuado de rotulación por la Resolución Mercosur GMC 26/03.

La propuesta de limitar la fortificación a las harinas destinadas a panificación encontró fuerte resistencia, entre otros, en la Sociedad Pediátrica Argentina, la cual manifestó mediante carta a la presidenta de la Comisión del Senado, ${ }^{26}$ la inconveniencia de adoptar el proyecto, por varias razones, entre ellas:

1. En la Argentina, nacen al año entre cuatrocientos y quinientos niños con defectos del tubo neural; dado que uno de cada dos embarazos no es planificado, y que los hábitos alimentarios no aseguran un consumo diario adecuado de ácido fólico, la OMS recomienda fortificar los alimentos de consumo masivo;

2. Los resultados de la Encuesta Nacional de Nutrición indican que los fideos secos y los derivados de la harina son los alimentos que más consumen las mujeres en edad fértil;

3. Si se quitara la fortificación de pastas, galletitas, bizcochos, la ingesta de folatos disminuiría en un 43\%, siendo a todas luces insuficiente para cubrir los requerimientos señalados;

4. Un estudio dirigido por la Dra. Ingrid Waisman de la SAP, concluyó que las mujeres en edad fértil consumen unos 481 microgramos diarios de ácido fólico, y antes de la entrada en vigor de la ley 25.630 los defectos del tubo neural afectaban 1 de cada 1.000 ó 1.200 nacimientos, y luego de la entrada en vigor de la ley los casos disminuyeron en una proporción del 50 por ciento.

5. Se alega que siendo que el problema lo genera el sulfato ferroso y no el ácido fólico, puede solucionarse exceptuando de la fortificación a ciertos productos de impacto menos masivo, como las tapas de empanadas.

\section{COLOFÓN}

Así las cosas, la discusión está planteada. Como se señalaba ha trascendido que se estudian modificaciones al proyecto aprobado por Diputados.

Debe tenerse presente que establecer políticas públicas en clave de género implica tener en cuentas las especiales necesidades, en este caso, de las mujeres en edad fértil,

26 Noticia recogida del diario La Nación, edición del día 27 de noviembre de 2008 , sección información general y de la web de la SAP, visitada el día 27 de noviembre de 2008. http/ www.sap.org.ar. 
que tienen requerimientos nutricionales específicos en un período de su vida. Y que la norma busca proteger a las mujeres en situación de vulnerabilidad económica, que no tiene acceso a una alimentación suficiente y balanceada y mucho menos a suplementos nutricionales, al fortificar las harinas con las que se hacen los alimentos de consumo básico y este no se trata sólo del pan sino especialmente de las pastas (fideos).

El cuadro se ve agravado por la regulación penal del aborto, que no reconoce como causal autónoma la del aborto motivado en graves defectos del feto; por lo cual una mujer pobre, que debe recurrir al sistema público de salud, embarazada de un feto con un grave defecto incompatible incluso con la vida extrauterina, como puede ser el caso de la anencefalia, debe afrontar un embarazo generador de un grave riesgo para su salud mental y física. Eso sin contar que no recibirá apoyo económico del Estado en caso que el feto nazca con un defecto grave, mas no mortal como puede ser la espina bífida por citar sólo un ejemplo, sumando ese niño o niña la discapacidad a las causas de vulnerabilidad ya expuestas.

Este tipo de normas muestra además que existen modos eficaces de proteger la vida y la salud del concebido sin afectar la dignidad de la madre, recurriendo a medios jurídicos diferentes de la penalización del aborto, método cuya eficacia como medida tutelar en los términos en los que se encuentra implementado actualmente es sin duda cuestionable.

Creemos que las razones expuestas en este breve trabajo, junto a otras que sin duda surgirán en el debate, ameritan un cuidadoso tratamiento de este proyecto de ley y una búsqueda exhaustiva de los recursos tecnológicos que permitan cristalizar la solución que mejor tutele la dignidad y el derecho a la salud de millones de personas. 